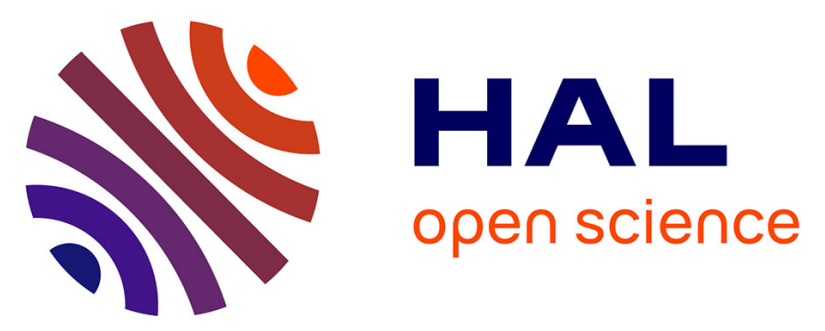

\title{
Anatomical, functional, and quality-of-life results for mastoid and epitympanic obliteration with bioactive glass S53P4: A prospective clinical study
}

Daniele Bernardeschi, Nadya Pyatigorskaya, Francesca Yoshie Russo, Daniele de Seta, Giulia Corallo, Evelyne Ferrary, Yann Nguyen, Olivier Sterkers

\section{To cite this version:}

Daniele Bernardeschi, Nadya Pyatigorskaya, Francesca Yoshie Russo, Daniele de Seta, Giulia Corallo, et al.. Anatomical, functional, and quality-of-life results for mastoid and epitympanic obliteration with bioactive glass S53P4: A prospective clinical study. Clinical Otolaryngology, 2016, 10.1111/coa.12748. hal-01368941

\section{HAL Id: hal-01368941 \\ https: / hal.sorbonne-universite.fr/hal-01368941}

Submitted on 20 Sep 2016

HAL is a multi-disciplinary open access archive for the deposit and dissemination of scientific research documents, whether they are published or not. The documents may come from teaching and research institutions in France or abroad, or from public or private research centers.
L'archive ouverte pluridisciplinaire HAL, est destinée au dépôt et à la diffusion de documents scientifiques de niveau recherche, publiés ou non, émanant des établissements d'enseignement et de recherche français ou étrangers, des laboratoires publics ou privés. 
ANATOMICAL, FUNCTIONAL, AND QUALITY-OF-LIFE RESULTS FOR MASTOID

AND EPITYMPANIC OBLITERATION WITH BIOACTIVE GLASS S53P4: A PROSPECTIVE CLINICAL STUDY

Short title: Mastoid and epitympanic obliteration with bioactive glass

Daniele Bernardeschi ${ }^{1,2,3}$, Nadya Pyatigorskaya ${ }^{2,4}$, Francesca Yoshie Russo ${ }^{1,2,3}$, Daniele De Seta $^{1,2,3}$, Giulia Corallo ${ }^{5}$, Evelyne Ferrary ${ }^{1,2,3}$, Yann Nguyen ${ }^{1,2,3}$ and Olivier Sterkers ${ }^{1,2,3}$

1. AP-HP, Groupe hospitalier Pitié-Salpêtrière, Service d'Oto-Rhino-Laryngologie, département d'Otologie, Implants auditifs et Chirurgie de la base du crâne, F-75013, Paris, France

2. Sorbonne Universités, UPMC Univ Paris 06, F-75005, Paris, France

3. Inserm UMR-S 1159, «Réhabilitation chirurgicale mini-invasive et robotisée de l'audition», F-75018, Paris, France

4. AP-HP, Groupe hospitalier Pitié-Salpêtrière, Service de neuroradiolgie, F-75013, Paris, France

5. Department of Otolaryngology, University of Siena, Siena, Italy

\section{Corresponding author:}

Daniele Bernardeschi, MD, PhD

Otology, auditory implants and skull base surgery department

Pitié-Salpêtrière Hospital 
50/52 Bd Vincent Auriol

75013 - Paris - France

Tel: +33 (0)142162603

Fax: + $33(0) 142162605$

E-mail: daniele.bernardeschi@psl.aphp.fr 


\section{ABSTRACT}

Objective: To analyze the anatomical, functional and quality-of-life results when using bioactive glass in mastoid and epitympanic obliteration.

Design: Prospective clinical study.

Setting: Tertiary referral center.

Participants: Forty-one cases (39 patients) operated between May 2013 and January 2015.

Main outcome measures: Anatomical results were evaluated by otomicroscopy 1 year after surgery and using imaging to detect residual disease. Functional results were studied by postoperative hearing gain. Quality of life was assessed with the Glasgow Benefit Inventory questionnaire and the success of surgery by a surgery-specific questionnaire.

Results: At 1 year, all patients presented a well-healed external auditory canal, with an intact tympanic membrane. In cases with cholesteatoma $(n=23)$, no recurrent retraction pockets or residual disease were observed on imaging studies. The overall air-bone gap closure was $7.7 \pm$ $1.84 \mathrm{~dB}$ (mean \pm standard error of the mean, $\mathrm{p}<0.001$, paired $t$-test). No significant differences were found on hearing results when comparing primary vs revision surgery, canalwall-up vs canal-wall-down obliterations, type of tympanoplasty, and presence of cholesteatoma (multi-factor ANOVA).

The Glasgow Benefit Inventory improved with an average score of 28 and the success of surgery questionnaire showed a significant improvement in ear discharge and a moderate improvement in hearing and equilibrium.

Conclusions: The use of bioactive glass for mastoid and epitympanic obliteration in canalwall-down or canal-wall-up tympanoplasties is an effective procedure in both primary and 
revision surgery. The anatomical and functional results appear to be well correlated with patient experience and to the improvement in quality of life. 


\section{INTRODUCTION}

Mastoid and epitympanic obliteration has been proposed for the rehabilitation of a canal-walldown mastoidectomy to avoid cavity-related drawbacks. Otorrhea, difficulty in fitting a hearing aid when needed, and vertigo or imbalance due to thermal stimulation of the posterior labyrinth are often undesirable outcomes of a canal-wall-down mastoidectomy ${ }^{1-3}$. Obliteration has also been performed in canal-wall-up mastoidectomy, though less frequently, to reduce the recurrence and residual rate of cholesteatoma in adults and children ${ }^{4,5}$ and to facilitate middle ear aeration ${ }^{6}$ after a closed technique with insufficient post-operative middle ear aeration. In both canal-wall-down and canal-wall-up mastoidectomies, obliteration of the paratympanic spaces reduces the mucosal surface thus slowing gas absorption and pressure changes responsible for recurrence, and improving long-term surgical outcome ${ }^{6}$.

Many materials have been used for obliteration, either autologous (cartilage, bone paté, bone chips, fat, muscular flaps) or biocompatible (bone substitutes, titanium, silicon blocks, hydroxyapatite cement). The bioactive glass S53P4 (BG) is a bone-substitute, silica-based biomaterial composed of a mixture of oxides $\left(53 \% \mathrm{SiO}_{2}, 23 \% \mathrm{Na}_{2} \mathrm{O}, 20 \% \mathrm{CaO}\right.$, and $4 \%$ $\mathrm{P}_{2} \mathrm{O}_{5}$ ). It is osteoconductive and osteoproductive ${ }^{7}$, and has the unique property of being antibacterial to many aerobic, anaerobic and multiresistent bacteria ${ }^{8}$. The inhibition of bacterial growth is probably due to the release of ions at the first stage of implantation that causes elevation of $\mathrm{pH}$ and osmotic pressure. BG granules have been used as bone graft substitute in various clinical applications ${ }^{9}$. Beside these interesting properties, which have established the material as a first-line choice when using biocompatible materials in obliterative surgeries, only three reports ${ }^{10-12}$ have been published concerning ear surgery, and only one was a prospective study. The safety of the granules of BG with regard to inner ear and skin tolerance has already been published ${ }^{13}$. 
The aim of this prospective study was to analyze the anatomical, functional, radiological and quality-of-life results of mastoid and epitympanic obliteration using the BG in primary and revision canal-wall-down and canal-wall-up mastoidectomies. 


\section{MATERIALS AND METHODS}

\section{Ethical considerations}

This study was authorized by the ethical institutional board, and all patients gave their written consent for the use of their personal clinical data. The BG used in this clinical trial was produced by BonAlive ${ }^{\circledR}$ Biomaterials Ltd (Turku, Finland) and was approved for clinical use in Europe in 2004 and in the United States in 2007.

\section{Study design}

This prospective, observational uncontrolled study was carried out between May 2013 and January 2015 in a tertiary referral center. Inclusion criteria were all the canal-wall-down (primary or revision) surgeries (Fig. 1A) performed in this period with obliteration using granules of BG and canal-wall-up mastoidectomies requiring obliteration for the stabilization of an attic reconstruction after a large atticotomy (Fig. 1B).

Typesetters: Please insert Figure 1 here

The surgical technique has been described previously ${ }^{13}$. Briefly, in both canal-wall-up and canal-wall-down mastoidectomies, obliteration of the paratympanic spaces, using granules of BG of $0.5-0.8 \mathrm{~mm}$ in diameter, followed:

- Removal of the lesions (cholesteatoma and/or inflammatory mucosa);

- Extensive drilling of the cavities until healthy bone was reached with removal of all visible pathologic mucosa;

- Reconstruction of the middle ear (tympanic drum + ossiculoplasty when needed).

All of the BG granules in contact with the skin of the external auditory canal were carefully covered by cartilage and fibrous tissue. The type of tympanoplasty was classified as: Type I (myringoplasty with no ossicular chain reconstruction), type II (partial ossicular replacement 
prosthesis used on an intact stapes), type III (total ossicular replacement prosthesis used on an intact footplate), and type IV (platinectomy with fibrous tissue interposition and placement of a total ossicular replacement prosthesis). Titanium prosthesis (Aerial Kurz ${ }^{\circledR}$, Tubingen, Germany) of adapted length was used when needed. Intraoperative intravenous antibioprophylaxis with amoxicillin/clavulanate was performed in all patients after having performed intraoperative bacteriological tests on othorrea, cholesteatoma matrix (if present), mastoid skin (in case of revision canal-wall-down procedure) and middle ear/mastoid mucosa. Oral treatment with amoxicillin/clavulanate was continued until it was adapted to the results of the intraoperative bacteriological test; if there were no pathogenic bacteria, antibiotherapy was stopped. If some pathogenic bacteria were found, the oral antibiotherapy was adapted to the antibiogram and delivered for 14 days following recommendations for chronic otitis ${ }^{19}$ and cochlear implant surgeries ${ }^{28}$ with mastoid obliteration. Ear drops of ofloxacine were administered to all patients for 1 month. Perioperative complications were noted, as well as the presence of cholesteatoma.

Anatomical results were evaluated with otomicroscopy 3 months and 1 year after surgery: the presence of a well-healed external auditory canal with no visible granules of BG and an intact tympanic membrane was considered to indicate a successful procedure. In the case of cholesteatoma, a computed tomography (CT) scan and non-echo-planar diffusion-weighted magnetic resonance imaging $(\mathrm{MRI})^{14}$ were also performed 1 year after surgery to detect residual disease in the middle ear and/or in the filled spaces.

Functional results were evaluated using the air-bone gap ( $\mathrm{ABG}$ ) closure, defined as the difference between pre-operative and post-operative $A B G$. The $A B G$ was calculated as recommended by the committee on hearing and equilibrium using pure-tone audiometry (mean of 500,1000, 2000, $4000 \mathrm{~Hz}$ ) in both air-conduction and bone-conduction conditions. 
Quality of life was evaluated 1 year after surgery through two questionnaires: the Glasgow Benefit Inventory $(\mathrm{GBI})^{15}$, and a surgery-specific questionnaire ${ }^{16}$. The GBI measures the changes in health status produced by surgery and it was divided into three subgroups (general, social support and physical health) and the results were reported from -100 to +100 for each subgroup and for the global score with zero being no change as a result of the intervention, 100 maximal deterioration and +100 being maximum quality-of-life improvement.

The surgery-specific questionnaire encompassed four questions:

1) Compared with before your ear surgery, how is your ear drainage?

2) Compared with before your ear surgery, how is your ear hearing?

3) Compared with before your ear surgery, how is your equilibrium?

4) Would you recommend this surgery to a family member?

The possible answers for the first three questions were noted using a Likert scale ranging from 1 to 5 ( 1 = dramatically worse; $2=$ somewhat worse; $3=$ not changed; $4=$ somewhat improved; 5 = dramatically improved). For the last question, possible answers were: $1=$ would discourage; $2=$ unlikely to recommend; 3 = indifferent; $4=$ likely to recommend; $5=$ highly recommended.

\section{Statistical analysis}

Data were presented as mean \pm standard error of the mean (SEM). Comparison between preand post-operative results was done with a paired $t$-test. A multi-factor ANOVA was used to analyze the influence of different tympanoplasty subgroups (type I, II, III and IV), the presence or not of a cholesteatoma, and primary vs revision surgery on ABG closure. Differences in quality of life (GBI scores) between primary and revision surgery were analyzed using the Mann-Whitney $U$-test. 
For all comparisons, $p<0.05$ was considered to indicate a statistically significant difference. All statistical analyses were performed using IBM SPSS for Windows (v 22.0, SPSS Inc., Chicago, Illinois, USA). 


\section{RESULTS}

\section{Participants}

Forty-one cases (39 patients, two operated bilaterally) were included (Table 1): there were 22 males and 17 females. The mean age was $46 \pm 2.5$ years (range 16-79 years). There were 25 right side and 16 left side cases. Thirty-six cases (88\%) were revision surgeries; the median number of previous surgeries was 2 (range 1-5). Of these 36 revision cases, 26 cases (72\%) had already been operated with a canal-wall-down mastoidectomy, whereas 10 (28\%) were previously operated with an intact canal wall technique.

Typesetters: Please insert Table 1 here

\section{Intraoperative findings}

Revision cases $(n=36)$ underwent revision canal-wall-down mastoidectomy in 26 cases (72\%), a canal-wall-down mastoidectomy in six cases (17\%), and a canal-wall-up mastoidectomy in four cases $(11 \%)$.

Primary cases $(n=5)$ were operated on with an open technique in three cases $(60 \%)$ and with a closed technique in two cases (40\%). Overall, an open technique was obliterated in 35 cases $(85 \%)$, whereas a closed technique in six cases (15\%). Tympanoplasty type I was performed in five cases (12\%), type II in 19 cases (46\%), type III in 14 cases (34\%), and type IV in 3 cases three cases (8\%). Cholesteatoma was found in 23 cases $(56 \%)$.

Perioperative complications occurred in seven cases (17\%). There were six cases (15\%) where an opening of the inner ear occurred during surgery: two cases of a pre-operative identified fistula of the lateral semicircular canal, three cases of a fractured/absent stapes footplate who underwent type IV tympanoplasty, and one case of round window membrane opening during dissection of the cholesteatoma invading the sinus tympani and 
hypotympanum. In one case (2\%), cerebrospinal fluid (CSF) leakage occurred during dissection of the skin over a tegmen tympani defect.

\section{Anatomical results}

Three months after surgery, 34 cases (83\%) presented a well-healed external auditory canal with an intact tympanic drum (Fig.2); two cases (5\%) presented a narrow but functional external auditory canal with an intact tympanic drum. Four ears $(10 \%)$ presented various degrees of lateralization of the tympanic drum. Only one patient $(2 \%)$ presented uncovered granules in the external auditory canal and underwent revision surgery 5 months after the first surgery, under local anesthesia, to cover the granules with cartilage. At 1 year, he had a wellhealed external auditory canal and tympanic drum.

Typesetters: Please insert Figure 2 here

At 1 year after surgery, these results were unchanged. No cases of recurrent cholesteatoma and/or retraction pocket were observed. In the post-operative CT (Fig. 3) and MRI studies $(n=23)$, no residual disease was found at 1 year after surgery.

Typesetters: Please insert Figure 3 here

\section{Functional results}

Pre-operative hearing status for each patient is detailed in Table 1. The pre-operative airconduction and bone-conduction pure-tone averages were $59 \pm 3.2 \mathrm{~dB}$ and $32 \pm 2.7 \mathrm{~dB}$ respectively. Patients with opening of the membrane of the round window experienced immediate total ipsilateral hearing loss. Post-operative pure-tone averages $(n=40$, deaf patient excluded) were $47 \pm 3.6 \mathrm{~dB}$ and $27 \pm 2.8 \mathrm{~dB}$ for air and bone conduction, respectively. There 
was no statistically significant difference between pre- and post-operative bone conduction threshold (paired $t$-test). The mean ABG closure was $7.7 \pm 1.84 \mathrm{~dB}$ and the difference was statistically significant $(\mathrm{p}<0.001$, paired $t$-test). Detailed functional results following type of tympanoplasty, primary vs revision surgery, canal-wall-up vs canal-wall-down, and presence vs absence of cholesteatoma are shown in Table 2 . No statistically significant differences were found in the $\mathrm{ABG}$ closure when comparing the different types of tympanoplasty, primary vs revision surgery, canal-wall-up vs canal-wall-down procedures, and the presence vs absence of cholesteatoma (NS, multi-factor ANOVA).

Typesetters: Please insert Table 2 here

\section{Questionnaires}

The overall quality of life improved after epitympanic or mastoid obliteration. The overall GBI score was $28 \pm 3.6$ (range -22 to 78 ); three patients had a negative score indicating a worsening of the quality of life. No statistically significant differences were found when comparing primary vs revision surgeries (Mann-Whitney $U$-test) (Table 4). Detailed results for each question are shown in Table 3.

Typesetters: Please insert Tables 3 and 4 here

Regarding the surgery-specific questionnaire, the median values of the responses were 5, 4, 4, and 5 for discharge, hearing, equilibrium, and recommendation, respectively, showing a significant improvement in the discharge of the ear felt by the patient. There was also a moderate improvement in hearing and equilibrium and almost all patients highly recommended such an operation. Detailed results are shown in Table 5. 
Typesetters: Please insert Table 5 here 


\section{DISCUSSION}

The goals of cholesteatoma surgery are the complete eradication of the disease, preventing a recurrence, and maintaining or restoring hearing. A canal-wall-down procedure is often the results of multiple operations to achieve these objectives, exposing the patient to cavityrelated problems.

Mastoid obliteration is used to reduce the recurrence and the residual rate in primary cholesteatoma surgery using both canal-wall-up ${ }^{4,5}$ and canal-wall-down procedures ${ }^{17-19}$. Moreover, obliteration of an unstable mastoid cavity leads to significantly better results for discharge $^{1,20,21}$, hearing rehabilitation ${ }^{22}$ and imbalance ${ }^{3}$ than a revision canal-wall-down procedure $^{23}$

Since $1911^{24}$, many materials, either autologous or biocompatible, have been used for obliteration. The disadvantages of using autologous materials are donor-site morbidity and the risk of resorption over time ${ }^{25}$. Using biocompatible materials, the most feared complication is infection and its subsequent extrusion. This is why the antibacterial activity of BG granules to the most frequent bacteria involved in chronic otitis seemed very attractive to us.

\section{Synopsis of key findings}

This study shows that the obliteration of both canal-wall-up and canal-wall-down procedures in primary or revision surgery is an effective technique and the initial results showed no adverse effects.

Regarding anatomical results, no infection of the implanted material has been reported with the necessity for removal of the BG granules. An intact external auditory canal with a well healed tympanic membrane was achieved in most of our patients. Various degrees of lateralization of the tympanic membrane can be expected, especially in multi-operated ears. A narrow external auditory canal was found in 2 cases; this was probably the result of the 
bulging of the postero-superior wall of the external auditory canal that is sometimes observed one month after surgery; in such a case an insertion of an expandable sponge packing with eardrops containing corticosteroids for two weeks can help in achieving an appropriate conformation of the external auditory canal.

No recurrence was seen within the study follow-up period (with a maximum follow-up of three years) or residual disease in post-operative imaging studies.

Regarding functional results, an overall improvement in hearing was achieved, even though not spectacular. Considering that most of our cases were revision surgeries, our results are in line with the reported literature ${ }^{18,19,25}$, and the reconstructed external auditory canal allowed changes in external ear resonance ${ }^{26}$ and facilitated the use of hearing aids ${ }^{22}$.

For quality of life, an overall significant improvement was observed in all procedures. The

results of the GBI questionnaires are similar to those obtained in other studies ${ }^{16,27}$ with a significant improvement in quality of life and this improvement is similar when considering primary and revision cases. Results for the surgery-specific questionnaire showed a marked improvement in the discharge of the ear, and mild or no improvement in hearing and balance, thus permitting a good correlation between objective and subjective results.

\section{Comparison with other studies}

Only three studies have been published which use BG in ear surgery, but none simultaneously report anatomical, functional and quality-of-life results.

In 2010 , Stoor et al. ${ }^{10}$ retrospectively analyzed seven cases of obliteration of discharging cavities reporting good skin tolerance and no infection of the implanted material. In $2012^{12}$, the same department retrospectively analyzed 25 cases (including the seven cases previously published with longer follow-up) treated over a 15-year period; $92 \%$ of patients has a dry 
smaller cavity after the operation but no statistical analysis was performed with regard to hearing. Finally, the only prospective study was performed by Silvola ${ }^{11}$ who reported on 14 patients treated with BG granules between 2007 and 2011 using different surgical techniques; he achieved a dry ear in all patients.

\section{Strengths of the study}

To our knowledge, this is the first prospective study on a large cohort of patients treated for mastoid and epitympanic obliteration in a short time with the same surgical technique. Analyzing both objective and subjective data allows a better comprehension and evaluation of the results, both anatomically and functionally. The quality of life and success of surgery questionnaires are essential when reporting results in chronic ear surgery.

\section{Study limitations}

The short 1-year follow-up is the main limitation of the study, especially when considering recurrence/residual results, but this is inevitable when performing a prospective study in a tertiary referral center. For patients with longer follow-up, anatomical results remain stable, but 5-year follow-up is necessary to evaluate the long-term results of the obliteration.

Moreover, the results of questionnaires could be overrated due to patient complacency.

\section{Clinical applicability of the study}

Despite its limitations, this study demonstrates that BG is an effective material for mastoid and epitympanic obliteration with no infection in the present series and with anatomical and functional results that are well correlated with the improvement in quality of life.

Conflicts of interest: none declared. 


\section{REFERENCES}

1 Harun A., Clark J., Semenov Y.R. et al. (2015) The role of obliteration in the achievement of a dry mastoid bowl. Otol. Neurotol. 36, 1510-1517.

2 Gluth M.B., Metrailer A.M., Dornhoffer J.L. et al. (2012) Patterns of failure in canal wall down mastoidectomy cavity instability. Otol. Neurotol. 33, 998-1001.

3 Beutner D., Helmstaedter V., Stumpf R. et al. (2010) Impact of partial mastoid obliteration on caloric vestibular function in canal wall down mastoidectomy. Otol. Neurotol. 31, 1399-1403.

4 van Dinther J.J.S., Vercruysse J.-P., Camp S. et al. (2015) The bony obliteration tympanoplasty in pediatric cholesteatoma: long-term safety and hygienic results. Otol. Neurotol. 36, 1504-1509.

5 Vercruysse J.-P., De Foer B., Somers T. et al. (2010) Long-term follow up after bony mastoid and epitympanic obliteration: radiological findings. J. Laryngol. Otol. 124, 3743.

6 Csakanyi Z., Katona G., Konya D. et al. (2014) Middle ear gas pressure regulation: the relevance of mastoid obliteration. Otol. Neurotol. 35, 944-953.

7 Välimäki V.V. \& Aro H.T. (2006) Molecular basis for action of bioactive glasses as bone graft substitute. Scand. J. Surg. 95, 95-102.

8 Drago L., De Vecchi E., Bortolin M. et al. (2015) Antimicrobial activity and resistance selection of different bioglass S53P4 formulations against multidrug resistant strains. Future Microbiol. 10, 1293-1299.

9 van Gestel N. a. P., Geurts J., Hulsen D.J.W. et al. (2015) Clinical applications of S53P4 bioactive glass in bone healing and osteomyelitic treatment: a literature review. BioMed Res. Int. 2015, 684826. 
10 Stoor P., Pulkkinen J. \& Grénman R. (2010) Bioactive glass S53P4 in the filling of cavities in the mastoid cell area in surgery for chronic otitis media. Ann. Otol. Rhinol. Laryngol. 119, 377-382.

11 Silvola J.T. (2012) Mastoidectomy cavity obliteration with bioactive glass: a pilot study. Otolaryngol. Head Neck Surg. 147, 119-126.

12 Sarin J., Grénman R., Aitasalo K. et al. (2012) Bioactive glass S53P4 in mastoid obliteration surgery for chronic otitis media and cerebrospinal fluid leakage. Ann. Otol. Rhinol. Laryngol. 121, 563-569.

13 Bernardeschi D., Nguyen Y., Russo F.Y. et al. (2015) Cutaneous and labyrinthine tolerance of bioactive glass S53P4 in mastoid and epitympanic obliteration surgery: prospective clinical study. BioMed Res. Int. 2015, 242319.

14 De Foer B., Vercruysse J.-P., Bernaerts A. et al. (2008) Detection of postoperative residual cholesteatoma with non-echo-planar diffusion-weighted magnetic resonance imaging. Otol. Neurotol. 29, 513-517.

15 Robinson K., Gatehouse S. \& Browning G.G. (1996) Measuring patient benefit from otorhinolaryngological surgery and therapy. Ann. Otol. Rhinol. Laryngol. 105, 415-422.

16 Dornhoffer J.L., Smith J., Richter G. et al. (2008) Impact on quality of life after mastoid obliteration. Laryngoscope 118, 1427-1432.

17 Mercke U. (1987) The cholesteatomatous ear one year after surgery with obliteration technique. Am. J. Otol. 8, 534-536.

18 Walker P.C., Mowry S.E., Hansen M.R. et al. (2014) Long-term results of canal wall reconstruction tympanomastoidectomy. Otol. Neurotol. 35, e24-30.

19 Bernardeschi D., Nguyen Y., Mosnier I. et al. (2014) Use of granules of biphasic ceramic in rehabilitation of canal wall down mastoidectomy. Eur. Arch. Otorhinolaryngol. 271, $59-64$. 
20 Yung M.W. (1996) The use of hydroxyapatite granules in mastoid obliteration. Clin. Otolaryngol. Allied Sci. 21, 480-484.

21 Alves R.D., Cabral Junior F., Fonseca A.C. de O. et al. (2016) Mastoid obliteration with autologous bone in mastoidectomy canal wall down surgery: a literature overview. Int. Arch. Otorhinolaryngol. 20, 76-83.

22 Gluth M.B., Friedman A.B., Atcherson S.R. et al. (2013) Hearing aid tolerance after revision and obliteration of canal wall down mastoidectomy cavities. Otol. Neurotol. 34, $711-714$.

23 Irving R.M., Gray R.F. \& Moffat D.A. (1994) Bone pâté obliteration or revision mastoidectomy: a five-symptom comparative study. Clin. Otolaryngol. Allied Sci. 19, $158-160$.

24 Mosher H. (1911) A method of filling the excavated mastoid with a flap from the back of the auricle. Laryngoscope 21, 1158-1163.

25 Liu S.-C., Wang C.-H. \& Huang B.-R. (2015) Obliteration of radical cavities and total reconstruction procedure without staging after canal wall down mastoidectomy: long-term results. Clin. Exp. Otorhinolaryngol. 8, 230-236.

26 Jang C.H. (2002) Changes in external ear resonance after mastoidectomy: open cavity mastoid versus obliterated mastoid cavity. Clin. Otolaryngol. Allied Sci. 27, 509-511.

27 Kurien G., Greeff K., Gomaa N. et al. (2013) Mastoidectomy and mastoid obliteration with autologous bone graft: a quality of life study. J. Otolaryngol. Head Neck Surg. 42, 49.

28 Bernardeschi D., Nguyen Y., Smail M., et al. (2015) Middle ear and mastoid obliteration for cochlear implant in adults: indications and anatomical results. Otol. Neurotol. 36, 604-609. 
Fig. 1. An example of a right canal-wall-down (A) and left canal-wall-up (B) mastoidectomy obliterated with granules of bioactive glass (black star). In the canal-wall-down mastoidectomy (A), cartilage (white star) is used to cover the granules in the new external auditory canal filled with resorbable mesh (white arrow). In the canal-wall-up mastoidectomy (B), granules are used to stabilize the attic reconstruction after a large atticotomy (black arrow) after reconstruction of the middle ear with a titanium total ossicular replacement prosthesis (white arrow).

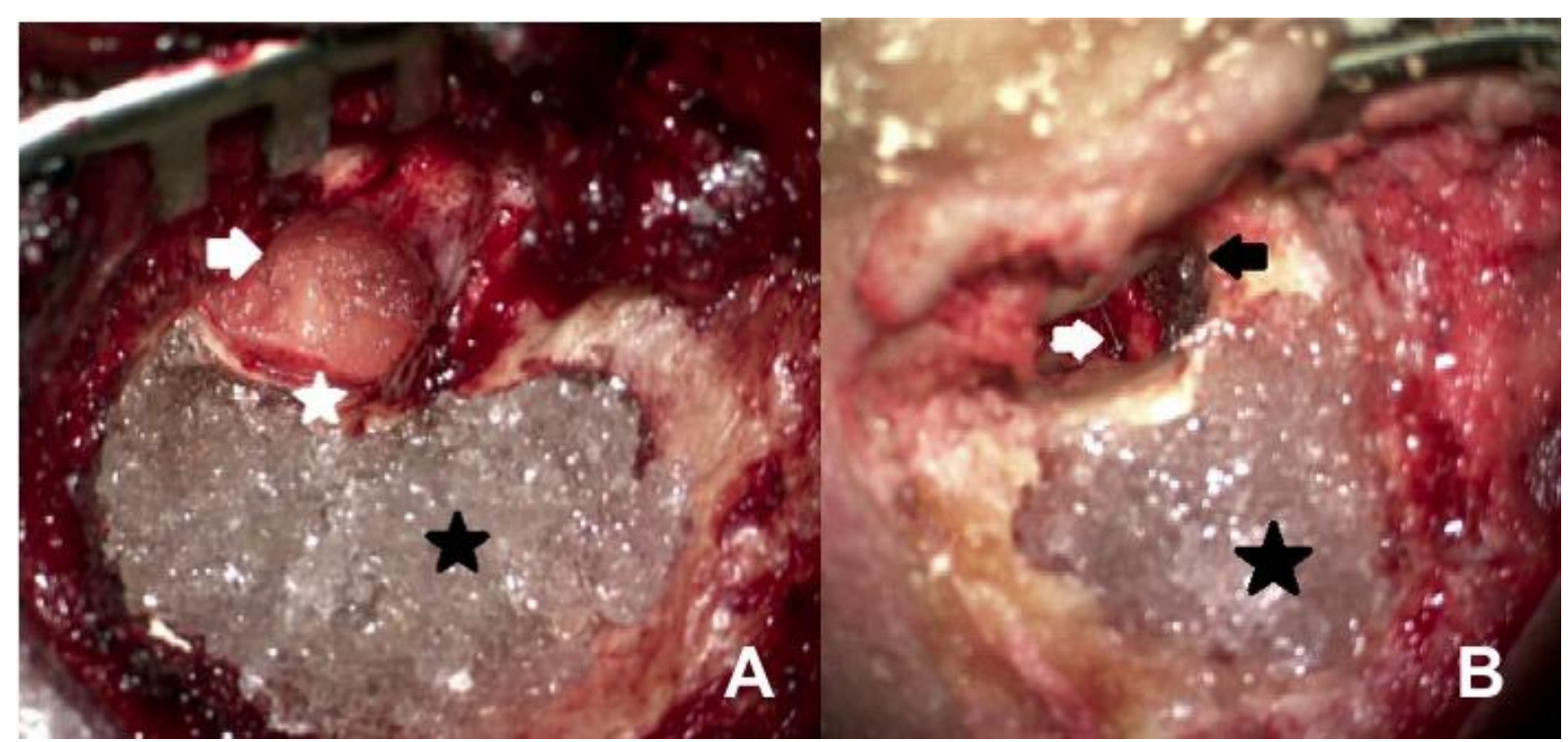


Fig. 2. An example of 1-year otoscopy of a right canal-wall-down (A) and left canal-wall-up (B) mastoidectomy obliterated with granules of bioactive glass. In the canal-wall-down mastoidectomy (A), black dotted lines indicate the reconstruction of the postero-superior canal wall and the black star the cartilage used for the reinforcement of the tympanic drum. In the canal-wall-up mastoidectomy (B), the black arrow indicates the cartilage used to reconstruct a large atticotomy (dotted lines); mastoid and epitympanic obliteration is performed in these cases for the stabilization of the attic reconstruction.

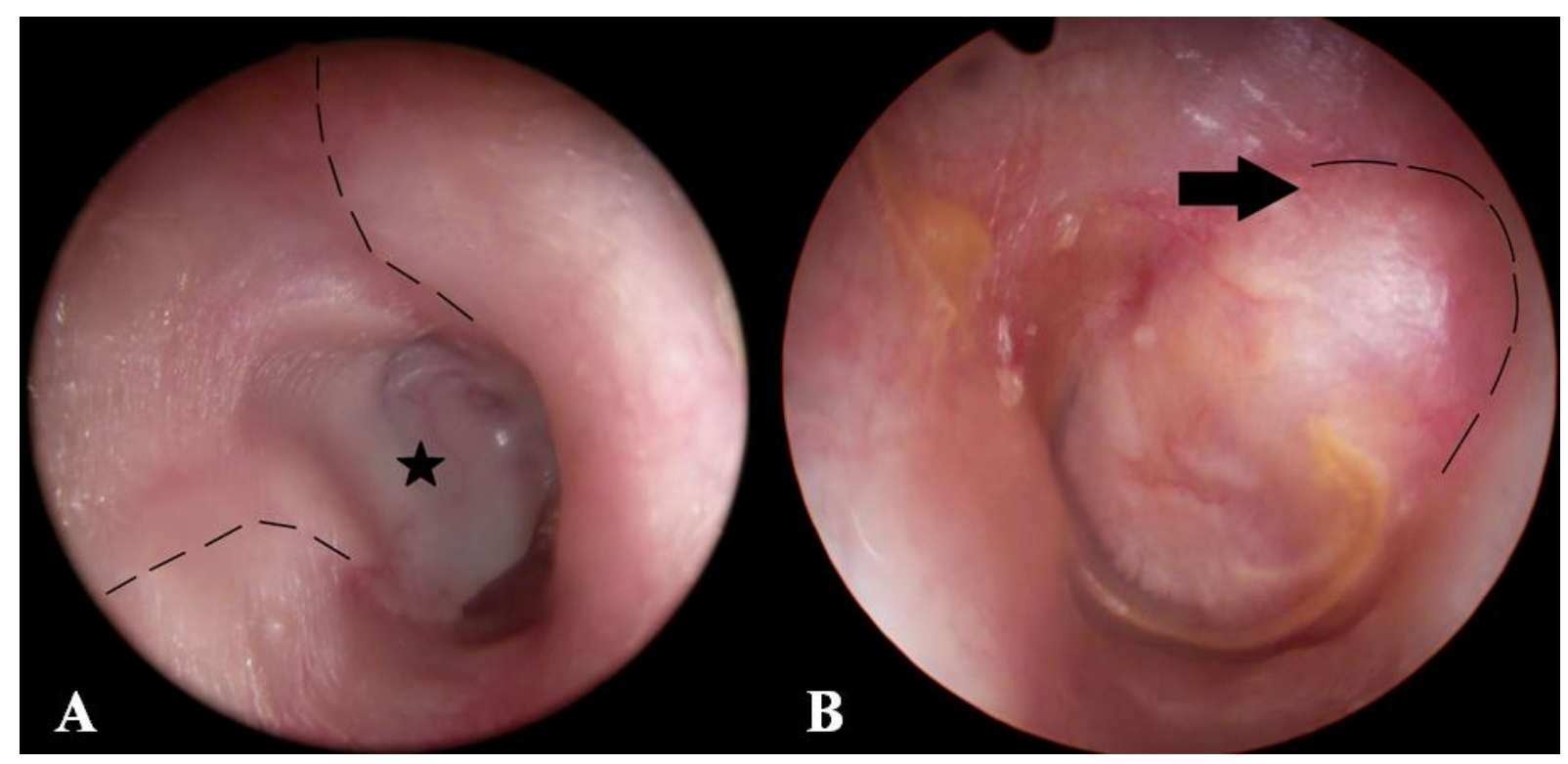


Fig. 3. High resolution CT scan in axial (A) and coronal (B) plane performed one year after surgery showing the complete obliteration of the paratympanic spaces and a well-aerated middle ear with partial ossicular replacement prosthesis in place.

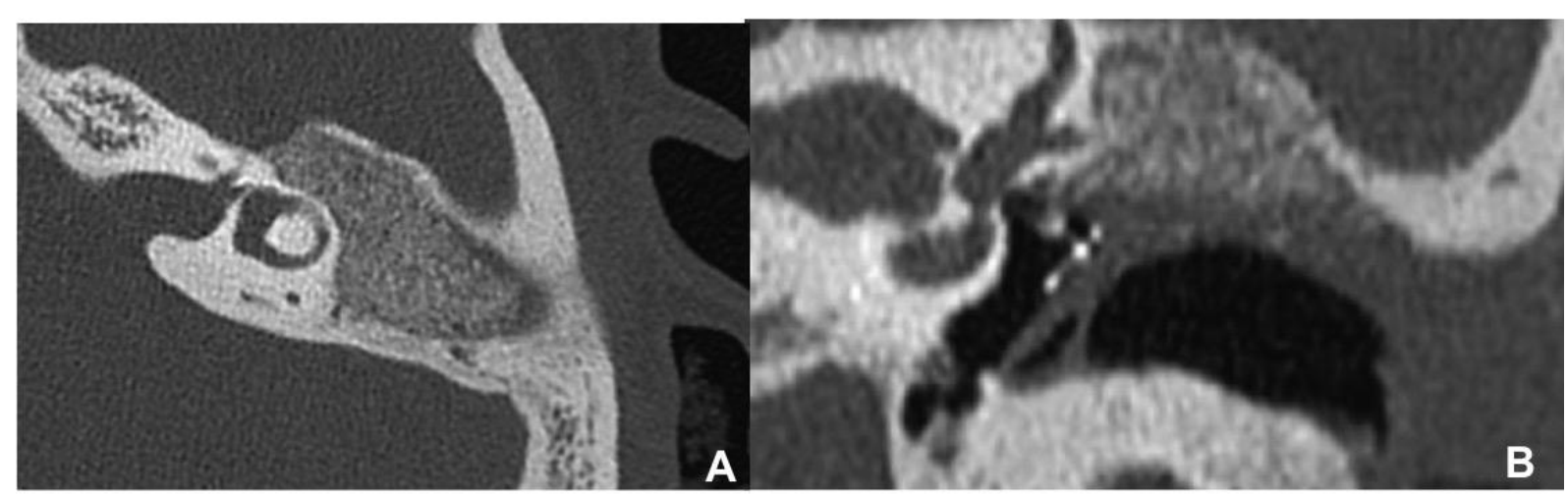


Table 1. Patient demographics, pre-operative physical examination and hearing status, post-operative anatomical and functional results

\begin{tabular}{|c|c|c|c|c|c|c|c|c|c|c|c|c|c|}
\hline \multirow[b]{2}{*}{ Patient } & \multicolumn{4}{|c|}{ Pre-operative } & \multicolumn{4}{|c|}{ Surgery } & \multicolumn{5}{|c|}{ One-year results } \\
\hline & $\begin{array}{l}\text { No. of } \\
\text { previous } \\
\text { surgerie } \\
\quad \text { S }\end{array}$ & $\begin{array}{c}\text { Open } \\
\text { cavity }\end{array}$ & $\begin{array}{c}\text { BC } \\
\text { Threshold } \\
\text { (dB) }\end{array}$ & $\begin{array}{l}\text { ABG } \\
(\mathbf{d B})\end{array}$ & Type of surgery & $\begin{array}{c}\text { Tym } \\
\text { pano } \\
\text { plast } \\
\text { y } \\
\text { type }\end{array}$ & $\begin{array}{c}\text { Cholesteatom } \\
\text { a }\end{array}$ & Complications & Otoscopy & $\begin{array}{c}\text { BC } \\
\text { Threshol } \\
\text { d (dB) }\end{array}$ & $\begin{array}{c}\text { ABG } \\
(\mathbf{d B})\end{array}$ & $\begin{array}{c}\text { ABG } \\
\text { closure }\end{array}$ & $\begin{array}{l}\text { Global GBI } \\
\text { score }\end{array}$ \\
\hline 1 & 3 & Yes & 18.75 & 27.5 & Revision CWD & 1 & No & No & Well healed & 27,5 & 22.5 & 5 & 30.55 \\
\hline 2 & 1 & No & 18.75 & 20 & CWD & 2 & Yes & No & Well healed & 7,5 & 17.5 & 2.5 & 66.66 \\
\hline 3 & 3 & Yes & 20 & 32.5 & Revision CWD & 1 & No & No & Well healed & 45 & 22.5 & 10 & 58.33 \\
\hline 4 & 0 & No & 25 & 20 & CWD & 2 & Yes & No & Well healed & 8,75 & 22.5 & -2.5 & 33.33 \\
\hline 5 & 2 & No & 48.75 & 42.5 & $\mathrm{CWU}$ & 3 & Yes & No & Well healed & 46,25 & 23.75 & 18.75 & 19.44 \\
\hline 6 & 0 & No & 22.5 & 32.5 & CWD & 3 & Yes & No & Well healed & 13,75 & 38.75 & -6.25 & 22.22 \\
\hline 7 & 3 & Yes & 37.5 & 31.25 & Revision CWD & 2 & Yes & No & Well healed & 45 & 6.25 & 25 & 77.77 \\
\hline 8 & 3 & Yes & 61.25 & 21.25 & Revision CWD & 4 & No & Platinectomy & Well healed & 38,75 & 36.25 & -15 & 61.11 \\
\hline 9 & 3 & Yes & 53.75 & 16.25 & Revision CWD & 2 & No & No & TD lateralization & 52,5 & 20 & -3.75 & 33.33 \\
\hline 10 & 2 & Yes & 20 & 35 & Revision CWD & 2 & Yes & No & Well healed & 11,25 & 18.75 & 16.25 & 58.33 \\
\hline 11 & 3 & Yes & 37.5 & 27.5 & Revision CWD & 4 & No & Platinectomy & Well healed & 28,75 & 21.25 & 6.25 & 19.44 \\
\hline 12 & 3 & Yes & 30 & 25 & Revision CWD & 3 & Yes & LSC fistula & Well healed & 18,75 & 23.75 & 1.25 & 16.66 \\
\hline 13 & 4 & Yes & 52.5 & 30 & Revision CWD & 4 & No & Platinectomy & Well healed & 23,75 & 12.5 & 17.5 & 55.55 \\
\hline 14 & 0 & No & 15 & 3.75 & CWU & 2 & Yes & No & Well healed & 15 & 6.25 & -2.5 & 25 \\
\hline 15 & 1 & Yes & 23.75 & 26.25 & Revision CWD & 1 & No & No & Well healed & 6,25 & 13.75 & 12.5 & 2.77 \\
\hline 16 & 1 & Yes & 22.5 & 21.25 & Revision CWD & 2 & No & No & Well healed & 15 & 3.75 & 17.5 & 47.22 \\
\hline 17 & 5 & Yes & 16.25 & 36.25 & Revision CWD & 2 & No & No & Well healed & 16,25 & 23.75 & 12.5 & 2.77 \\
\hline 18 & 3 & Yes & 18.75 & 26.25 & Revision CWD & 3 & Yes & No & Well healed & 8,75 & 11.25 & 15 & 44.44 \\
\hline 19 & 1 & No & 45 & 25 & CWU & 2 & Yes & No & Well healed & 32,5 & 20 & 5 & 5.55 \\
\hline 20 & 2 & Yes & 30 & 15 & Revision CWD & 3 & Yes & No & Well healed & 20 & 10 & 5 & 41.66 \\
\hline 21 & 3 & No & 33.75 & 13.75 & CWU & 2 & Yes & No & Well healed & 13,75 & 26.25 & -12.5 & 16.66 \\
\hline 22 & 3 & Yes & 38.75 & 20 & Revision CWD & 3 & No & No & Narrow EAC & 42,5 & 21.25 & -1.25 & 16.66 \\
\hline 23 & 4 & No & 15 & 42.5 & CWU & 2 & Yes & $\begin{array}{l}\text { Opening of the RW } \\
\text { membrane }\end{array}$ & Well healed & & $\begin{array}{l}\text { Anac } \\
\text { usis }\end{array}$ & & -19.4 \\
\hline 24 & 2 & Yes & 11.25 & 51.25 & Revision CWD & 2 & Yes & No & Well healed & 26,25 & 37.5 & 13.75 & 22.22 \\
\hline 25 & 3 & Yes & 30 & 43.75 & Revision CWD & 3 & No & No & Narrow EAC & 30 & 20 & 23.75 & 27.77 \\
\hline 26 & 3 & Yes & 16.25 & 37.5 & Revision CWD & 3 & No & No & TD lateralization & 27,5 & 25 & 12.5 & 25 \\
\hline 27 & 2 & Yes & 21.25 & 23.75 & Revision CWD & 3 & No & No & Well healed & 15 & 18.75 & 5 & 0 \\
\hline 28 & 1 & No & 8.75 & 22.5 & CWD & 2 & Yes & No & Well healed & 6,25 & 12.5 & 10 & 33.33 \\
\hline
\end{tabular}




\begin{tabular}{|c|c|c|c|c|c|c|c|c|c|c|c|c|c|}
\hline 29 & 3 & Yes & 21.25 & 41.25 & Revision CWD & 1 & Yes & No & Well healed & 17,5 & 11.25 & 30 & -2.77 \\
\hline 30 & 1 & Yes & 7.5 & 16.25 & Revision CWD & 3 & No & No & Well healed & 12,5 & 6.25 & 10 & 41.66 \\
\hline 31 & 2 & No & 27.5 & 31.25 & CWD & 3 & Yes & No & Well healed & 26,25 & 17.5 & 13.75 & 44.44 \\
\hline 32 & 2 & No & 35 & 20 & CWD & 2 & Yes & No & Well healed & 26,25 & 10 & 10 & 36.11 \\
\hline 33 & 3 & Yes & 36.25 & 15 & Revision CWD & 1 & Yes & No & Well healed & 35 & 23.75 & -8.75 & 22.2 \\
\hline 34 & 1 & No & 62.5 & 38.75 & CWD & 3 & Yes & LSC fistula & Well healed & 57,5 & 30 & 8.75 & 50 \\
\hline 35 & 1 & Yes & 55 & 35 & Revision CWD & 2 & No & No & Well healed & 38,75 & 26.25 & 8.75 & 2.77 \\
\hline 36 & 1 & Yes & 58.75 & 35 & Revision CWD & 2 & No & No & TD lateralization & 52,5 & 16.25 & 18.75 & 33.33 \\
\hline 37 & 0 & No & 31.25 & 43.75 & CWD & 2 & Yes & No & TD lateralization & 31,25 & 41.25 & 2.5 & 25 \\
\hline 38 & 0 & No & 13.75 & 12.5 & CWU & 2 & Yes & No & Well healed & 5 & 16.25 & -3.75 & 8.33 \\
\hline 39 & 2 & Yes & 25 & 13.75 & Revision CWD & 3 & No & CSF leak & Well healed & 27,5 & 15 & -1.25 & 8.33 \\
\hline 40 & 3 & No & 87.5 & 22.5 & CWD & 2 & Yes & No & Well healed & 92,5 & 32.5 & -10 & 50 \\
\hline 41 & 2 & Yes & 51.25 & 28.75 & Revision CWD & 3 & No & $\begin{array}{l}\text { Uncovered granules } \\
\text { at } 3 \text { months: } \\
\text { revision surgery }\end{array}$ & Well healed & 57,5 & 23.75 & 5 & -22.2 \\
\hline
\end{tabular}

BC, bone conduction; ABG, air-bone gap; CWU, canal-wall-up; CWD, canal-wall-down; LCS, lateral semicircular canal; RW, round window;

CSF, cerebrospinal fluid; TD, tympanic drum; EAC, external auditory canal; GBI, Glasgow Benefit Inventory. 
Table 2. Detailed functional results according to the type of surgery $(n=40$, deaf patient excluded)

\begin{tabular}{|c|c|c|c|c|c|}
\hline $\begin{array}{l}\text { Type of } \\
\text { surgery }\end{array}$ & $\begin{array}{c}\text { Pre- } \\
\text { operative } \\
\text { ABG }\end{array}$ & $\begin{array}{c}\text { Post- } \\
\text { operative } \\
\text { ABG }\end{array}$ & $\begin{array}{c}\text { ABG } \\
\text { closure }\end{array}$ & $\mathbf{N}$ & $\begin{array}{l}\text { Multi- } \\
\text { factor } \\
\text { ANOVA }\end{array}$ \\
\hline Primary & $22.5 \pm 7$ & $25 \pm 7$ & $-2.5 \pm 5$ & 5 & $\mathrm{~F}=2.61$, \\
\hline Revision & $28 \pm 2$ & $19 \pm 1$ & $9 \pm 2$ & 35 & $\mathrm{p}=0.11$ \\
\hline CWU & $20 \pm 7$ & $18.5 \pm 3$ & $1.5 \pm 5$ & 6 & $\mathrm{~F}=0.51$ \\
\hline CWD & $28 \pm 2$ & $20 \pm 1$ & $8 \pm 2$ & 34 & $\mathrm{p}=0.47$ \\
\hline Type1 & $28 \pm 4$ & $19 \pm 3$ & $10 \pm 6$ & 5 & \\
\hline Type2 & $26 \pm 3$ & $20 \pm 2$ & $6 \pm 2$ & 18 & $\mathrm{~F}=1.11$, \\
\hline Type 3 & $28 \pm 3$ & $20 \pm 2$ & $8 \pm 2$ & 14 & $\mathrm{p}=0.36$ \\
\hline Type 4 & $27 \pm 3$ & $24 \pm 7$ & $3 \pm 10$ & 3 & \\
\hline $\begin{array}{c}\text { Cholesteatoma } \\
\text { yes }\end{array}$ & $26 \pm 3$ & $21 \pm 2$ & $5 \pm 2$ & 22 & $\mathrm{~F}=0.2$ \\
\hline $\begin{array}{c}\text { Cholesteatoma } \\
\text { no }\end{array}$ & $27 \pm 2$ & $19 \pm 2$ & $8 \pm 2$ & 18 & $\mathrm{p}=0.81$ \\
\hline
\end{tabular}

Data are expressed in $\mathrm{dB}$ as mean \pm SEM. CWU, canal-wall-up; CWD, canal-wall-down; $\mathrm{ABG}=$ air-bone gap. 
Table 3. Glasgow Benefit Inventory (GBI) summary of results

\begin{tabular}{|l|l|l|l|l|l|l|l|}
\hline & & \multicolumn{3}{|l|}{ Number of respondents per answer } \\
\hline Question & Median & $\begin{array}{l}\text { Interquartile } \\
\text { range }\end{array}$ & 5 & 4 & 3 & 2 & 1 \\
\hline 1. Effect on life & 4 & 2 & 17 & 7 & 16 & 1 & 0 \\
\hline 2. Overall effect on life & 4 & 1 & 20 & 12 & 7 & 2 & 0 \\
\hline 3. Optimism about the future & 4 & 1 & 5 & 23 & 12 & 1 & 0 \\
\hline 4. Embarrassment & 4 & 1 & 5 & 16 & 18 & 2 & 0 \\
\hline 5. Self-confidence & 3 & 1 & 3 & 16 & 19 & 3 & 0 \\
\hline 6. Dealing with company & 3 & 1 & 6 & 13 & 19 & 3 & 0 \\
\hline 7. Support from friend & 3 & 1 & 4 & 8 & 28 & 1 & 0 \\
\hline 8. Visit to GP & 4 & 1 & 4 & 17 & 18 & 2 & 0 \\
\hline 9. Job opportunities & 3 & 1 & 4 & 9 & 25 & 3 & 0 \\
\hline 10. Self-consciousness & 3 & 0 & 1 & 8 & 28 & 4 & 0 \\
\hline 11. People who care & 3 & 0 & 0 & 4 & 33 & 2 & 2 \\
\hline 12. Frequency of illness & 3 & 1 & 5 & 13 & 19 & 3 & 1 \\
\hline 13. Frequency of medication & 4 & 1 & 9 & 14 & 16 & 2 & 0 \\
\hline 14. Self-opinion & 4 & 0 & 8 & 26 & 6 & 1 & 0 \\
\hline 15. Family support & 3 & 1 & 4 & 12 & 24 & 1 & 0 \\
\hline 16. Inconvenience & 4 & 2 & 11 & 17 & 10 & 3 & 0 \\
\hline 17. Social activities & 3 & 1 & 3 & 11 & 23 & 4 & 0 \\
\hline 18. Social situations & 3 & 1 & 2 & 11 & 24 & 4 & 0 \\
\hline GP, genal praction
\end{tabular}

GP, general practitioner. 
Table 4. Glasgow Benefit Inventory (GBI) subscale results by type of surgery

\begin{tabular}{|l|l|l|l|l|}
\hline & $\begin{array}{l}\text { Entire } \\
\text { cohort } \\
(\mathrm{n}=41)\end{array}$ & $\begin{array}{l}\text { Primary } \\
\text { surgery } \\
(\mathrm{n}=5)\end{array}$ & $\begin{array}{l}\text { Revision } \\
\text { surgery } \\
(\mathrm{n}=36)\end{array}$ & $\begin{array}{l}\text { Mann- } \\
\text { Whitney } \\
\text {-test }\end{array}$ \\
\hline Overall & 28 & 23 & 28 & NS \\
\hline General & 31 & 27 & 32 & NS \\
\hline Physical & 29 & 13 & 31 & NS \\
\hline Social & 13 & 17 & 12 & NS \\
\hline
\end{tabular}

Data are presented as mean values. 
Table 5. Results of success of surgery questionnaire

\begin{tabular}{|l|l|l|l|l|l|l|l|l|}
\hline & & & \multicolumn{4}{l|}{ Number of respondents per answer } \\
\hline Question & Median & $\begin{array}{l}\text { Interquartile } \\
\text { range }\end{array}$ & 5 & 4 & 3 & 2 & 1 \\
\hline Improved drainage & 5 & 0 & 34 & 2 & 4 & 1 & 0 \\
\hline Improved hearing & 4 & 2 & 14 & 12 & 7 & 6 & 2 \\
\hline Improved equilibrium & 4 & 1 & 9 & 13 & 17 & 2 & 0 \\
\hline Recommendation & 5 & 1 & 27 & 12 & 2 & 0 & 0 \\
\hline
\end{tabular}

Possible answers for the first three questions were $1=$ dramatically worse; $2=$ somewhat worse; $3=$ not changed; $4=$ somewhat improved; $5=$ dramatically improved. For the last question, possible answers were: $1=$ would discourage; $2=$ unlikely to recommend; $3=$ indifferent; 4 = likely to recommend; 5 = highly recommended. 